\title{
Erratum to upregulation of long noncoding RNA RAB11B-AS1 promotes tumor metastasis and predicts poor prognosis in lung cancer
}

Tiegang Li ${ }^{1,2}$, Di Wu ${ }^{1,3}$, Qun Liu ${ }^{1,3}$, Dedong Wang ${ }^{1}$, Jinbin Chen ${ }^{1}$, Hongjun Zhao ${ }^{1}$, Lan Zhang ${ }^{4}$, Chenli Xie ${ }^{5}$, Wei Zhu ${ }^{3}$, Zhixu Chen ${ }^{6}$, Yifeng Zhou ${ }^{7}$, Soham Datta ${ }^{1}$, Fuman Qiu ${ }^{1}$, Lei Yang ${ }^{1}$, Jiachun Lu ${ }^{1}$

${ }^{1}$ The State Key Lab of Respiratory Disease, The First Affiliated Hospital, The Institute for Chemical Carcinogenesis, School of Public Health, Guangzhou Medical University, Guangzhou, China; ${ }^{2}$ Institute of Lung Disease, Guangzhou Chest Hospital, Guangzhou, China; ${ }^{3}$ Guangzhou Center for Disease Control and Prevention, Guangzhou, China; ${ }^{4}$ Department of Medical Genetics and Cell Biology, GMU-GIBH Joint School of Life Sciences, Guangzhou Medical University, Guangzhou, China; ${ }^{5}$ Fifth People’s Hospital of Dongguan, Dongguan, China; ${ }^{6}$ Puning People’s Hospital, Puning, China; ${ }^{7}$ Department of Genetics, Medical College of Soochow University, Suzhou, China

Correspondence to: Jiachun Lu, MD, PhD. The State Key Lab of Respiratory Disease, The First Affiliated Hospital, The Institute for Chemical Carcinogenesis, School of Public health, Guangzhou Medical University, Xinzao Town, Panyu District, Guangzhou 511436, China. Email: jclu@gzhmu.edu.cn.

doi: $10.21037 /$ atm-2020-41

View this article at: http://dx.doi.org/10.21037/atm-2020-41

Erratum to: Ann Transl Med 2020;8:582

Upregulation of long noncoding RNA RAB11B-AS1 promotes tumor metastasis and predicts poor prognosis in lung cancer

In the article titled "Upregulation of long noncoding RNA RAB11B-AS1 promotes tumor metastasis and predicts poor prognosis in lung cancer" published in the Vol 8, No 9 (May 2020) of Annals Translational Medicine (1), Figure $3 A$ and Figure $3 B$ were wrong listed. 
In the original version of the article, the transwell migration images for (A549 lncRNA Downregulation), (PC9 lncRNA Upregulation), and (PC9 up control) in Figure 3A were accidentally misplaced. The transwell invasion image for (A549 lncRNA downregulation), (A549 down control), (PC9 up control), and (PC9 down control) in Figure 3B was placed by mistake.

A IncRNA Upregulation
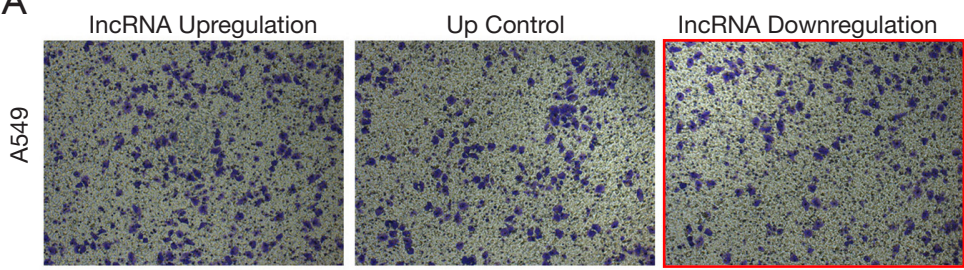

Down Control
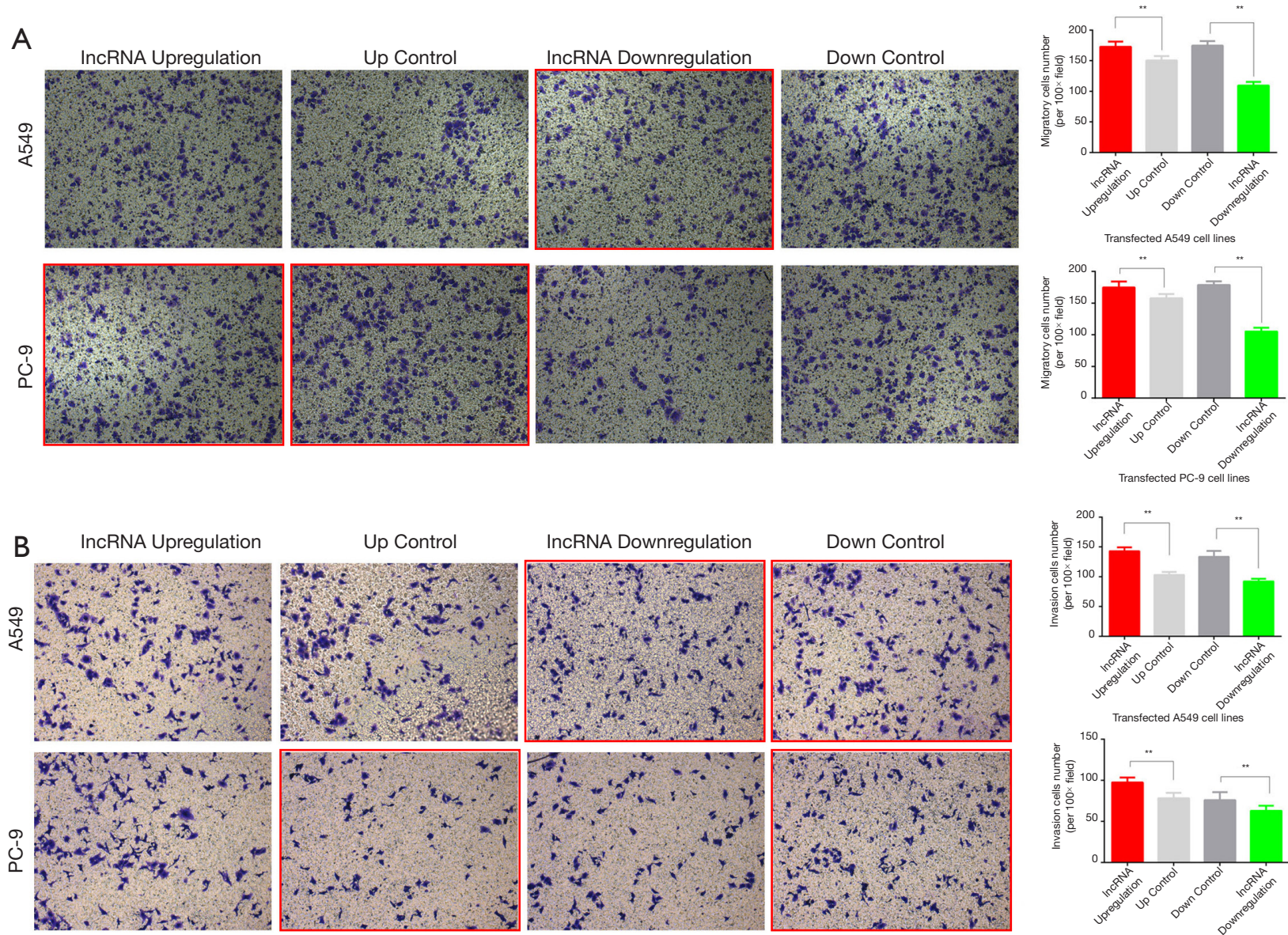

IncRNA Downregulation

Down Control
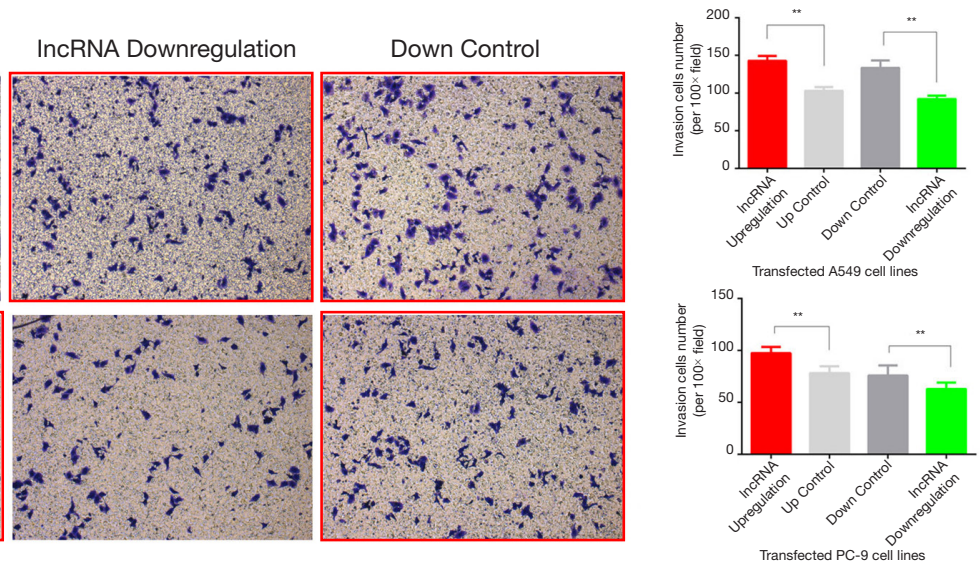
C

C IncRNA
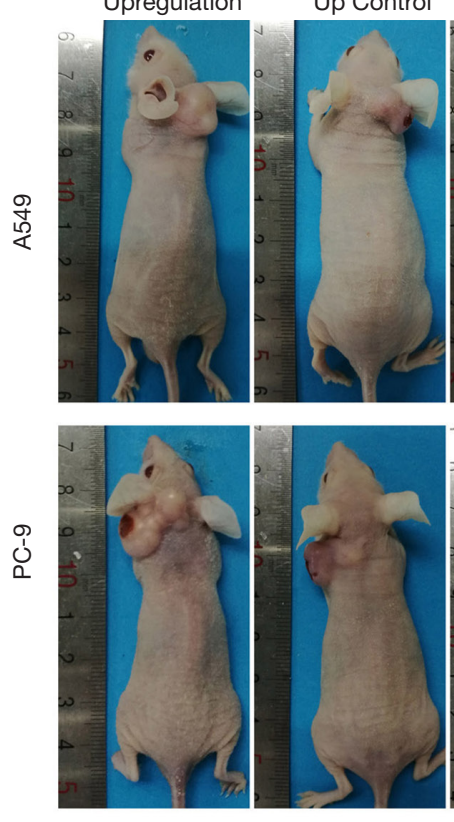

$\mathrm{D}$

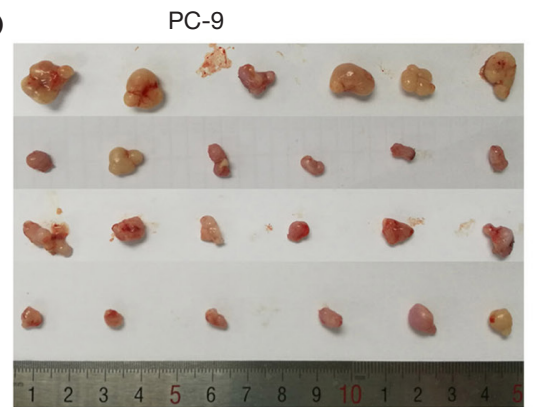

IncRNA
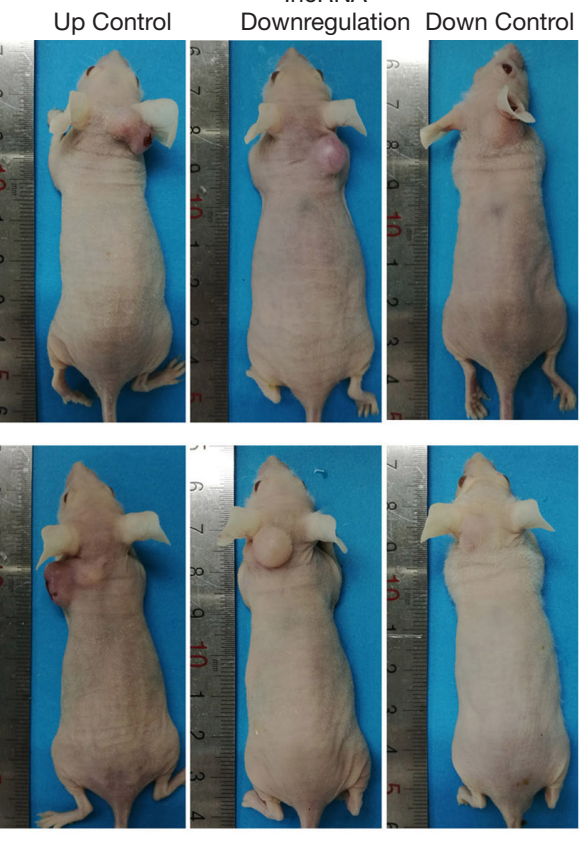

IncRNA Up

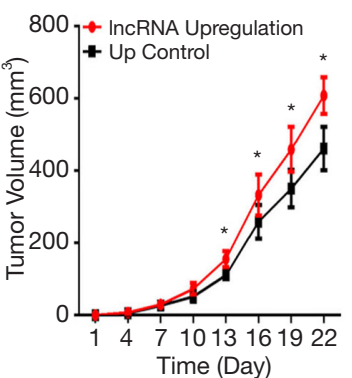

IncRNA Up

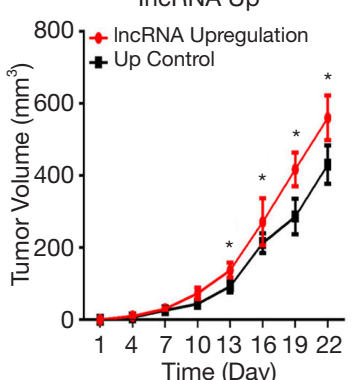

IncRNA Down

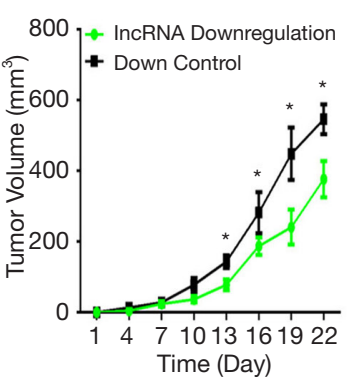

IncRNA Down

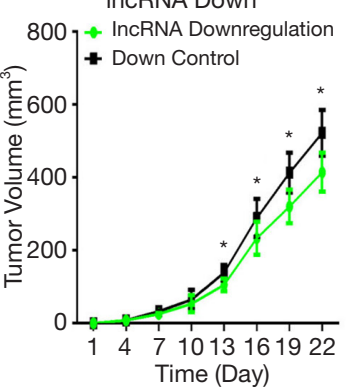

A549

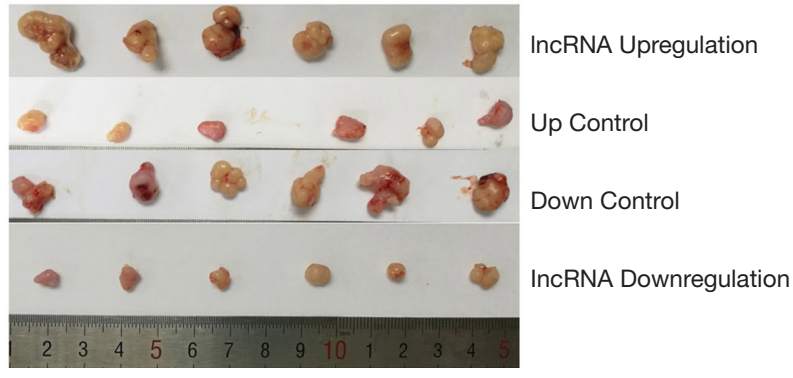


These mistakes happened when we prepared images using the wrong folders. We carefully rechecked our original data and confirmed that this error happened in figure making, and did not affect the results or conclusion of the study. Therefore, Figure $3 A$ and Figure $3 B$ should be corrected as below:

A
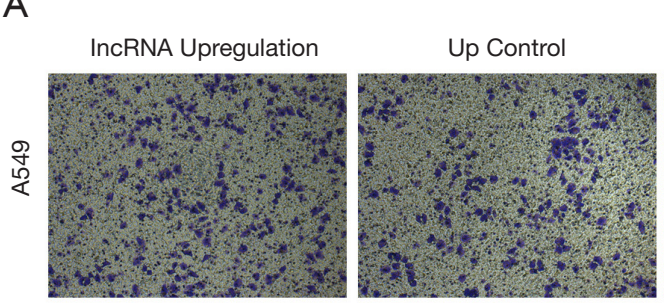

IncRNA Downregulation
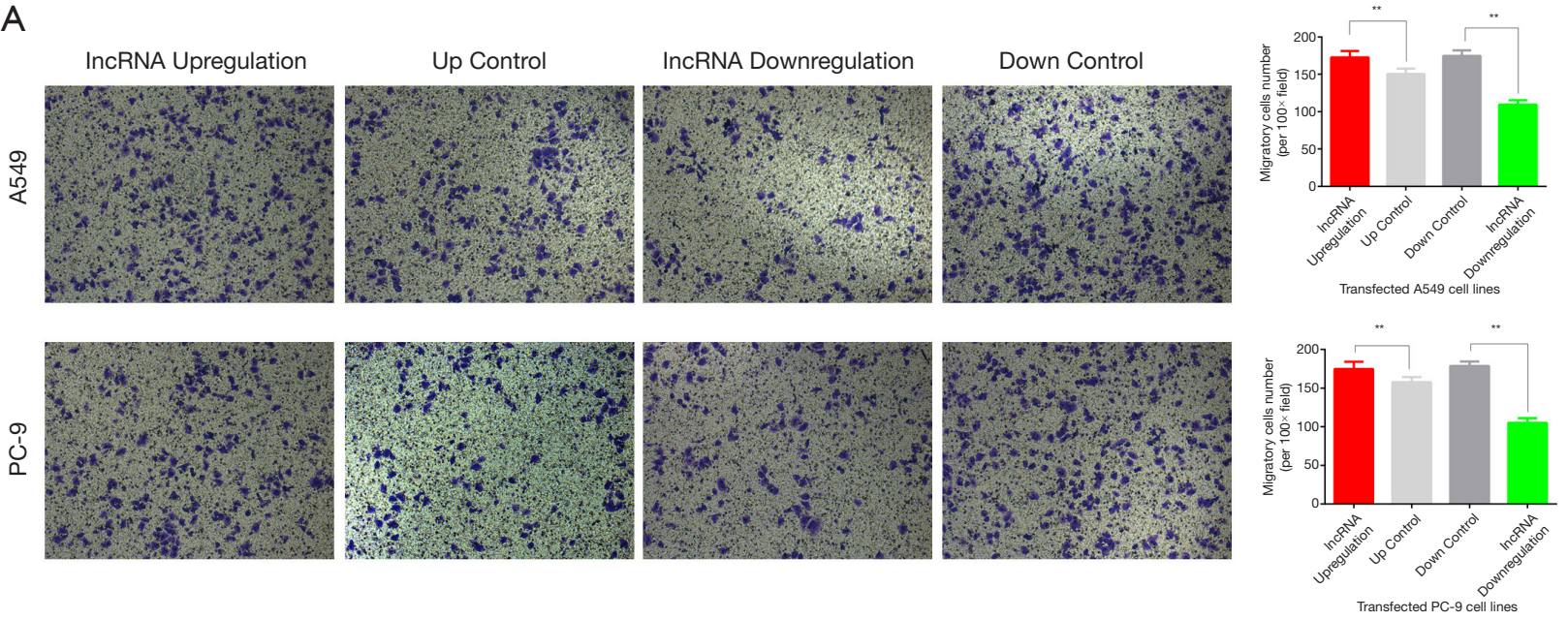

Figure $3 \mathrm{~A}$

B
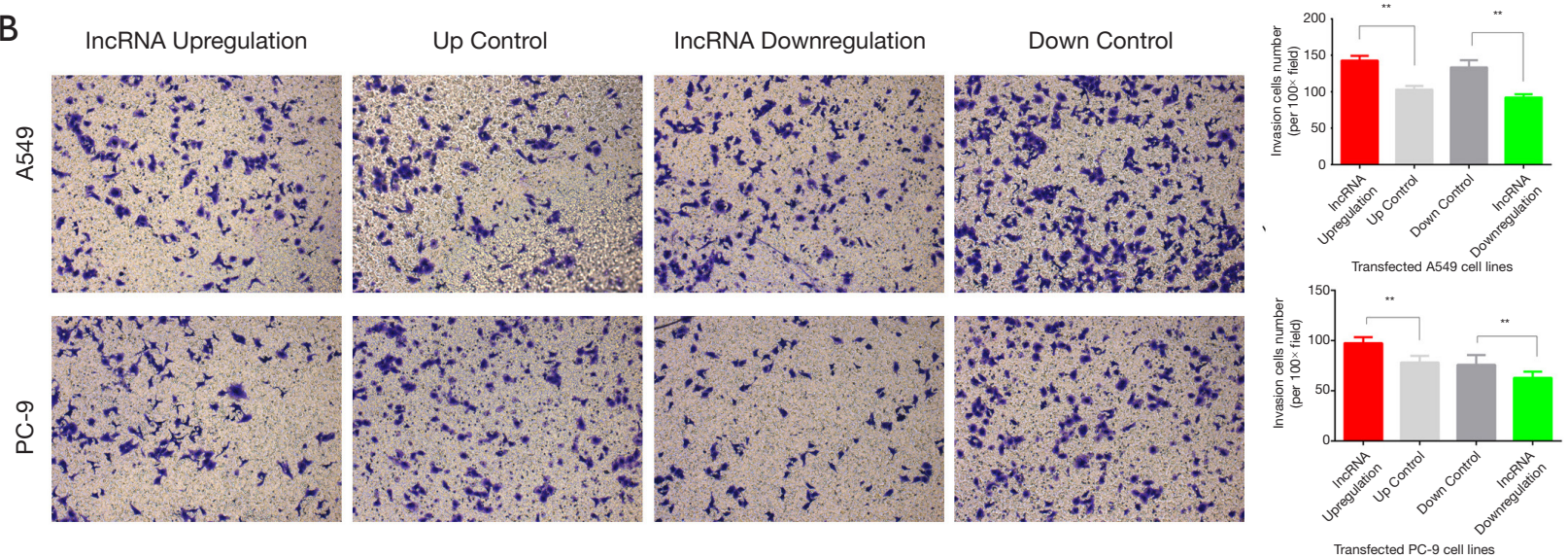

Figure 3B 
The corrected version of Figure 3 in whole is as below:

A
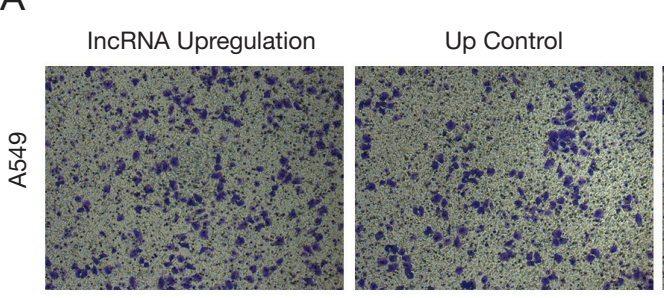

IncRNA Downregulation
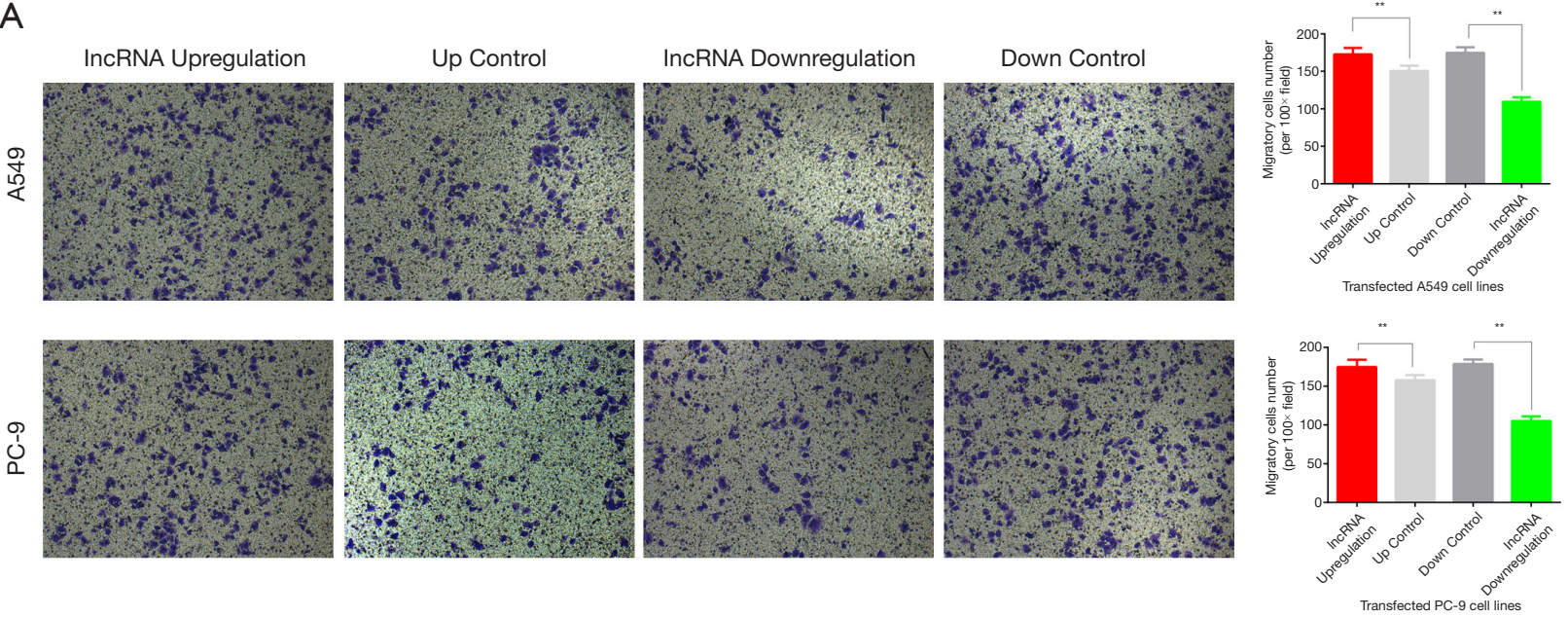

B
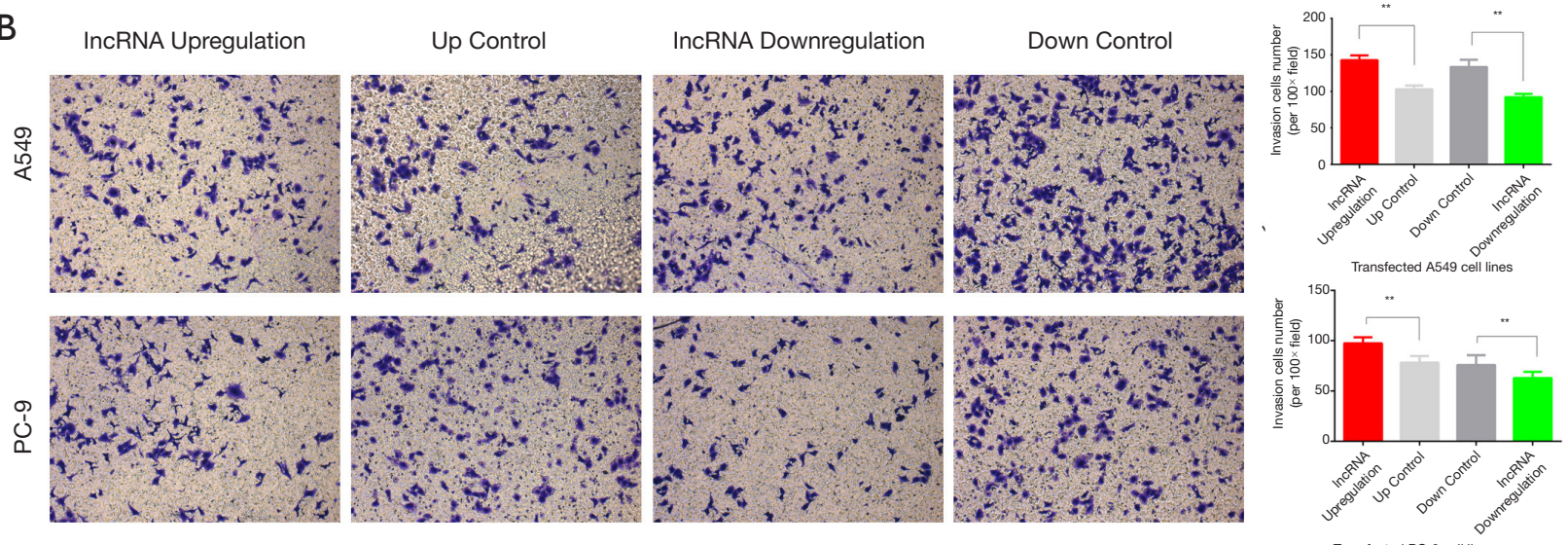

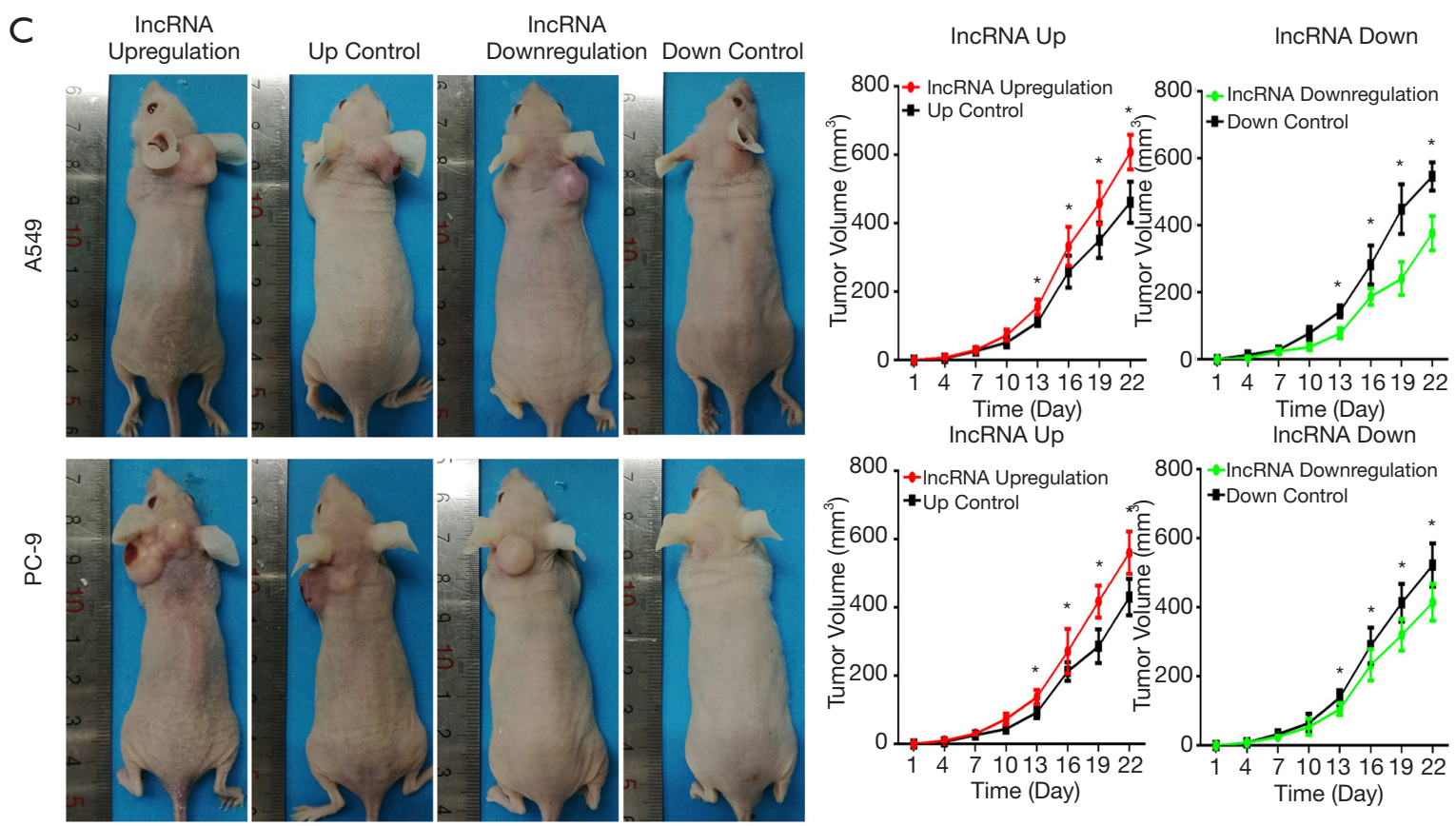

$\mathrm{D}$
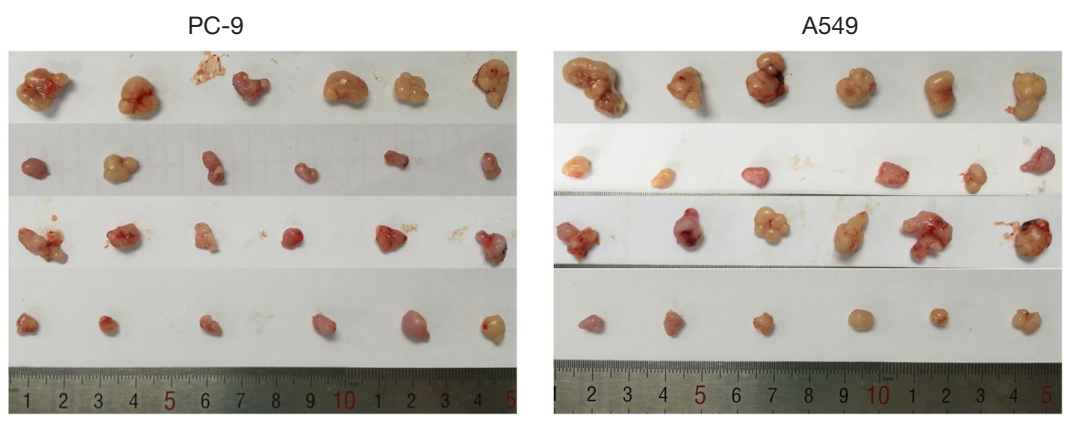

IncRNA Upregulation

Up Control

Down Control

IncRNA Downregulation

We have also submitted the experimental record, raw data, images and invoices of related reagents to the editorial office as proofs for this correction and a data sharing statement is provided in this Erratum. We apologize for the negligent errors and are very sorry for not being able to identify it at the submission and proofreading step and will strive to avoid similar mistakes in the future.

\section{Footnote}

Data Sharing Statement: Available at http://dx.doi.org/10.21037/atm-2020-41

Open Access Statement: This is an Open Access article distributed in accordance with the Creative Commons AttributionNonCommercial-NoDerivs 4.0 International License (CC BY-NC-ND 4.0), which permits the non-commercial replication and distribution of the article with the strict proviso that no changes or edits are made and the original work is properly cited (including links to both the formal publication through the relevant DOI and the license). See: https://creativecommons.org/licenses/by-ncnd/4.0/. 


\section{References}

1. $\quad \mathrm{Li}$ T, Wu D, Liu Q, et al. Upregulation of long noncoding RNA RAB11B-AS1 promotes tumor metastasis and predicts poor prognosis in lung cancer. Ann Transl Med 2020;8:582.

Cite this article as: $\mathrm{Li} \mathrm{T}, \mathrm{Wu} \mathrm{D}$, Liu Q, Wang D, Chen J, Zhao H, Zhang L, Xie C, Zhu W, Chen Z, Zhou Y, Datta S, Qiu F, Yang L, Lu J. Erratum to upregulation of long noncoding RNA RAB11B-AS1 promotes tumor metastasis and predicts poor prognosis in lung cancer. Ann Transl Med 2020;8(21):1475. doi: 10.21037/atm-2020-41 